\title{
Defining CT Perfusion Thresholds for Infarction in the Golden Hour and With Ultra-Early Reperfusion
}

\author{
Mohamed Najm, Fahad S. Al-Ajlan, Mari E. Boesen, Lisa Hur, Chi Kyung Kim, \\ Enrico Fainardi, Michael D. Hill, Andrew M. Demchuk, Mayank Goyal, Ting Y. Lee, \\ Bijoy K. Menon
}

\begin{abstract}
In this brief report, computed tomography perfusion (CTP) thresholds predicting follow-up infarction in patients presenting $<3$ hours from stroke onset and achieving ultra-early reperfusion ( $<45$ minutes from CTP) are reported. CTP thresholds that predict follow-up infarction vary based on time to reperfusion: Tmax $>20$ to 23 seconds and cerebral blood flow $<5$ to $7 \mathrm{ml} / \mathrm{min}^{-1} /(100 \mathrm{~g})^{-1}$ or relative cerebral blood flow $<0.14$ to 0.20 optimally predicted the final infarct. These thresholds are stricter than published thresholds.
\end{abstract}

RÉSUMÉ: Seuils limites d'un examen de tomodensitométrie couplé à une perfusion administré à des patients victimes d'un accident ischémique et aux prises avec un processus de reperfusion très précoce se présentant en temps opportun. Dans ce bref compte-rendu, il est question des seuils limites obtenus à la suite d'un examen de tomodensitométrie couplé à une perfusion. Ces seuils limites peuvent prédire le suivi de patients ayant subi un accident ischémique. Les patients à l'étude devaient s'être présentés moins de 3 heures après l'apparition de l'accident ischémique et avoir montré très tôt des signes de reperfusion (moins de 45 minutes à la suite d'un examen de tomodensitométrie). Les seuils limites pouvant prédire l'évolution de patients à la suite d'un accident ischémique vont varier selon le temps de reperfusion. Cela dit, une durée dépassant les 20 à 23 secondes et un débit sanguin cérébral inférieur à $5-7 \mathrm{ml} / \mathrm{min}^{-1} /(100 \mathrm{~g})^{-1}$ ou bien un débit sanguin cérébral relatif inférieur à $0,14-0,20$ ont permis de prédire de façon optimale un AVC. Précisons que ces seuils limites sont plus sévères que ceux ayant été publiés antérieurement.

Keywords: CT perfusion, endovascular therapy, early reperfusion

doi:10.1017/cjn.2017.287

Can J Neurol Sci. 2018; 45: 339-342

At the exact time a thrombus blocks an intracranial artery, downstream blood flow drops. Depending on collateral extent, ischemic brain can have regions of flow ranging from very low to near normal. Regions with very low blood flow are likely to infarct earlier; nonetheless, these brain regions will remain viable for a short period. Computed tomography perfusion (CTP) thresholds predicting infarction on follow-up brain scans are therefore likely to depend on how fast reperfusion is achieved, and could break down if reperfusion is achieved ultra-early.

With modern endovascular therapy and a strong focus on efficiency in workflow, ultra-early reperfusion is now achievable. ${ }^{1}$ Using data from a large prospective cohort study, we reported timebased CTP thresholds predicting follow-up infarction among patients achieving imaging to reperfusion in $<90$ minutes and $<180$ minutes, on average. ${ }^{2}$ In this analysis, using data from a subset of patients achieving ultra-early CTP-to-reperfusion time ( $<45$ minutes) and early onset to admission imaging ( $<3$ hours), we estimate CTP thresholds predicting follow-up brain infarction.

We queried the Prove-IT database for patients satisfying the following inclusion criteria: (1) >18 years of age; (2) complete anterior circulation proximal vessel occlusion; (3) TICI $2 b / 3$ reperfusion within 45 minutes of admission CTP; (4) onset to admission imaging within 180 minutes; and (5) 24-hour follow-up magnetic resonance-diffusion-weighted imaging preferably or noncontrast computed tomography (NCCT) if magnetic resonance imaging is not available. Demographic and clinical characteristics, imaging, and interval times were collected.

From the Calgary Stroke Program, Department of Clinical Neurosciences, University of Calgary, Calgary, Alberta, Canada (MN, FSA-A, LH, CKK, MDH, AMD, MG, BKM); Department of Radiology, University of Calgary, Calgary, Alberta, Canada (FSA-A, MDH, AMD, MG, TYL, BKM); Department of Community Health Sciences, University of Calgary, Calgary, Alberta, Canada (MDH, BKM); Hotchkiss Brain Institute, Calgary, Canada (MDH, AMD, MG, BKM); Seaman Family MR Research Centre, Foothills Medical Centre, Calgary, Alberta, Canada (MN, MEB, MDH, AMD, MG, BKM); Lawson Health Research Institute and Robarts Research Institute, London, Ontario, Canada (TYL); Department of Neurology, Korea University Guro Hospital, Seoul, South Korea (CKK); Department of Neurosciences, King Faisal Specialist Hospital \& Research Centre, Riyadh, Saudi Arabia (FSA-A); Neuroradiology Unit, Department of Diagnostic Imaging, Azienda Ospedaliero-Universitaria Careggi, Firenze, Italy (EF).

Part of these results was presented the 68th AAN Annual Meeting, April 15-21, 2016, Vancouver, BC, Canada.

Received July 4, 2017. Final Revisions Submitted July 27, 2017. Date of ACCEPTANCE OCTOBER 11, 2017.

Correspondence to: Bijoy K. Menon, Calgary Stroke Program, Department of Clinical Neurosciences, University of Calgary, 1079 A, 29th Street NW, Calgary, AB, Canada T2N2T9. Email: docbijoymenon@gmail.com 
A 64-slice CT scanner (Lightspeed; GE Healthcare, Waukesha, WI) was used for all CT imaging. NCCT, head/neck multiphase CT angiography, and CTP were performed at admission. NCCT and multislice CTA were done per described protocol. ${ }^{3}$ For the CTP protocol, $45 \mathrm{ml} \mathrm{CT} \mathrm{contrast} \mathrm{agent} \mathrm{(Optiray} \mathrm{320;}$ Mallinckrodt Pharmaceuticals, Dublin, Ireland) was power injected at $4.5 \mathrm{ml} / \mathrm{s}$ followed by a saline chase of $40 \mathrm{ml}$ at $6 \mathrm{ml} / \mathrm{s}$. An 8 $\mathrm{cm}$ slab of the brain in 5-mm-thick slices was scanned using two phases: a 2.8 -second interval for 60 seconds, then a 15 -second interval for 90 seconds.

Delay-insensitive deconvolution software (CT Perfusion 4D, GE Healthcare) was used for CTP processing. The arterial input function was manually selected from the basilar artery or internal carotid artery. Cerebral blood flow (CBF) $\left[\mathrm{ml} / \mathrm{min}^{-1} /(100 \mathrm{~g})^{-1}\right]$, cerebral blood volume $(\mathrm{CBV})\left[\mathrm{ml} /(100 \mathrm{~g})^{-1}\right]$, and Tmax (seconds) maps were calculated. ${ }^{2}$ Average maps were used for gray/white matter segmentation and as the source image for coregistration with follow-up imaging. ${ }^{2}$ CTP maps and follow-up images were coregistered using in-house software (Calgary Image Analysis and Processing Centre, Calgary, AB).

An expert radiologist $(\mathrm{CK})$ delineated the follow-up infarct, when present, on diffusion-weighted imaging $(n=5)$ or NCCT $(n=2)$ superimposed onto coregistered CTP functional maps. Method for optimal threshold derivation has been described previously. ${ }^{2}$ Briefly, voxel-level histograms were extracted from the infarct (region of interest-infarct) and the ipsilateral hemisphere minus the infarct (region of interest-salvaged). Receiver operating characteristic curve was generated from the histograms. Youden's method was then used to determine optimal threshold associated with follow-up infarction for each CTP parameter. Corresponding relative $\mathrm{CBF}$ thresholds were also calculated.

Seven patients satisfied inclusion criteria. Among these, three had onset to CTP $\leq 60$ minutes (golden hour), whereas four had onset to CTP 60 to 180 minutes. Median (range) onset to CTP time was 148 minutes (52-180 minutes), CTP to final reperfusion time was 41 minutes (29-45 minutes), admission National Institutes of Health Stroke Scale was 11 (6-17) (Table 1). Optimal CTP thresholds, stratified by onset-to-CTP time, along with c-statistics and sensitivities/specificities, are shown in Table 2. Tmax $>22$ to 23 seconds and $\mathrm{CBF}<5.5 \mathrm{ml} / \mathrm{min}^{-1} /(100 \mathrm{~g})^{-1}$ or relative CBF $<0.16$ were optimal when reperfusion was achieved in patients resenting in the golden hour and achieving reperfusion within
45 minutes of baseline CTP. CTP thresholds for patients presenting within 3 hours of symptom onset but beyond the golden hour still achieving ultra-early reperfusion are slightly more liberal (Table 2).

With better in-field triaging, efficient in-hospital workflow, and modern endovascular therapy, reperfusion times continue to get faster. Recently, we showed that a Tmax threshold of $>16$ seconds or absolute CBF threshold of $<9 \mathrm{ml} / \mathrm{min}^{-1} /(100 \mathrm{~g})^{-1}$ (relative $\mathrm{CBF}<0.23$ ) is associated with infarct if quality reperfusion is achieved within 90 minutes from CTP imaging. ${ }^{2}$ Herein, we show that CTP thresholds predicting follow-up infarction continue to evolve based on time to quality reperfusion. On average, Tmax $>20$ to 23 seconds and $\mathrm{CBF}<5$ to $7 \mathrm{ml} / \mathrm{min}^{-1} /(100 \mathrm{~g})^{-1}$ or relative $\mathrm{CBF}<0.14$ to 0.20 were optimal when reperfusion was achieved within 45 minutes of baseline CTP. These thresholds are lower than those for reperfusion within 90 minutes $^{2}$ and more stringent in the golden hour (Figure 1). Moreover, relative CBF thresholds from this analysis are much lower than current accepted thresholds. $^{4-6}$

Although recent studies, including ours, empirically report that CTP thresholds predictive of follow-up infarction do not vary substantively by onset to $\mathrm{CT}$ time, ${ }^{2,7}$ but depend on imaging to reperfusion time, our results show that Tmax and CBF thresholds predicting follow-up infarction become stricter (higher for Tmax, lower for $\mathrm{CBF}$ ) with early onset to imaging times. In our opinion, this could be because measurement onset time is more accurate the earlier a patient presents to hospital. We also note that the sensitivity and specificity of these thresholds in predicting infarct are slightly lower in the golden hour. Plausible explanation is that CTP measures blood flow rather than neuronal function and very early in the ischemic cascade the survival threshold is more heterogeneous if reperfusion can be established quickly. Interestingly, in the golden hour, the $\mathrm{CBV}$ parameter becomes as discriminative (c-statistic for gray matter and white matter of 0.81 and 0.80 , respectively), if not more than the other parameters. If CBV is low $\left(<2.6-2.7 \mathrm{ml} /(100 \mathrm{~g})^{-1}\right)$, then that tissue has a very high likelihood of irreversible infarction, even if reperfusion occurs in $<45$ minutes. Conversely, if CBV is $>2.7 \mathrm{ml} /(100 \mathrm{~g})^{-1}$ and reperfusion occurs in $<45$ minutes, then that tissue has a high likelihood of surviving. The effect that ultra-early presentation and reperfusion has on the predictive characteristics of CTP thresholds are illustrated in the Supplemental Figure.

Table 1: Admission demographics and workflow time metrics in the study $(n=7)$

\begin{tabular}{|c|c|c|c|c|c|c|c|c|c|}
\hline $\begin{array}{l}\text { Patient } \\
\text { no. }\end{array}$ & $\begin{array}{c}\text { Admission } \\
\text { NIHSS }\end{array}$ & $\begin{array}{c}\text { Location of } \\
\text { occlusion }\end{array}$ & $\begin{array}{c}\text { Collateral } \\
\text { scoring }\end{array}$ & $\begin{array}{c}\text { Final } \\
\text { mTICI }\end{array}$ & $\begin{array}{l}\text { CTP-to-first } \\
\text { rescan }(\mathrm{min})\end{array}$ & $\begin{array}{l}\text { Onset-to- } \\
\text { CTP (min) }\end{array}$ & $\begin{array}{c}\text { CTP-to-final } \\
\text { reperfusion (min) }\end{array}$ & $\begin{array}{c}\text { Onset to } \\
\text { reperfusion }(\mathrm{min})\end{array}$ & $\begin{array}{c}\text { Final } \\
\text { NIHSS }\end{array}$ \\
\hline 1 & 16 & Proximal M1 & 6 & $2 b$ & 22 & 56 & 29 & 85 & 1 \\
\hline 2 & 15 & Proximal M1 & 8 & 3 & 25 & 60 & 30 & 90 & 2 \\
\hline 3 & 17 & Proximal M1 & 6 & 3 & 16 & 52 & 45 & 97 & 2 \\
\hline 4 & 9 & Proximal M2 & 8 & $2 b$ & 35 & 148 & 41 & 189 & 0 \\
\hline 5 & 11 & Proximal M1 & 8 & 3 & 35 & 180 & 45 & 226 & 0 \\
\hline 6 & 6 & Proximal M2 & 9 & 3 & 23 & 122 & 43 & 165 & 0 \\
\hline 7 & 6 & Proximal M1 & 7 & 3 & 42 & 160 & 45 & 205 & 1 \\
\hline Median & 11 & & 8 & & 35 & 148 & 41 & 189 & 1 \\
\hline
\end{tabular}

$\mathrm{CTP}=$ computed tomography perfusion; $\mathrm{mTICI}=$ modified treatment in cerebral ischemia; NIHSS = National Institutes of Health Stroke Scale 
Table 2: Optimal CTP thresholds from voxel level data in patients achieving ultra-early reperfusion (CTP to reperfusion $<45$ minutes), stratified by imaging within "golden hour" (onset to CTP $\leq 60$ minutes) versus early (onset to CTP 60-180 minutes)

\begin{tabular}{|c|c|c|c|c|c|c|c|}
\hline \multirow[b]{2}{*}{$\begin{array}{l}\text { Onset to CTP time, } \\
\text { min }\end{array}$} & & \multicolumn{2}{|c|}{ Tmax } & \multicolumn{2}{|c|}{ Absolute CBF; relative CBF } & \multicolumn{2}{|c|}{ CBV } \\
\hline & & Gray matter & White matter & Gray matter & White matter & Gray matter & White matter \\
\hline$\leq 60$ & $\begin{array}{l}\text { Optimal threshold } \\
\text { AUC (CI) } \\
\text { Sensitivity, specificity }\end{array}$ & $\begin{array}{l}\quad 22.0 \\
0.76(0.75-0.77)^{*} \\
0.63,0.75\end{array}$ & $\begin{array}{l}\quad 23.6 \\
0.70(0.69-0.72)^{*} \\
0.67,0.61\end{array}$ & $\begin{aligned} & 5.5 ; 0.16 \\
& 0.80(0.79-0.81) \\
& 0.82,0.80\end{aligned}$ & $\begin{array}{l}\quad 5.2 ; 0.15 \\
0.79(0.78-0.82) \\
0.78,0.72\end{array}$ & $\begin{array}{l}\quad 2.7 \\
0.81(0.80-0.83) \\
0.80,0.81\end{array}$ & \begin{tabular}{l}
\multicolumn{1}{c}{2.6} \\
$0.80(0.79-0.82)$ \\
$0.79,0.73$
\end{tabular} \\
\hline $60-180$ & $\begin{array}{l}\text { Optimal threshold } \\
\text { AUC(CI) } \\
\text { Sensitivity, specificity }\end{array}$ & $\begin{array}{l}19.5 \\
0.91(0.91-0.92) \\
0.86,0.89\end{array}$ & $\begin{array}{l}\quad 20.4 \\
0.90(0.89-0.93) \\
0.90,0.89\end{array}$ & $\begin{array}{l}\quad 7.1 ; 0.19 \\
0.89(0.88-0.91) \\
0.83,0.82\end{array}$ & $\begin{array}{l}\quad 6.4 ; 0.20 \\
0.82(0.79-0.85) \\
0.81,0.87\end{array}$ & $\begin{array}{l}\quad 4.5 \\
0.52(0.50-0.53)^{*} \\
0.48,0.58\end{array}$ & $\begin{array}{l}\quad 3.5 \\
0.54(0.52-0.56)^{*} \\
0.58,0.59\end{array}$ \\
\hline
\end{tabular}

*Significantly different from other parameters in that strata.

$\mathrm{AUC}=$ area under the receiver operator characteristic curve (c-statistic); $\mathrm{CBF}=$ cerebral blood flow; $\mathrm{CI}=$ confidence interval; $\mathrm{CTP}=$ computed tomography perfusion

Ultra-early presentation and reperfusion is uncommon; we only identify seven such patients from a study of more than 500 patients. Nonetheless, the voxel-level analysis we performed gives our analysis some robustness. In summary, we show that with faster reperfusion time, CTP thresholds become more stringent. These stricter CTP thresholds may need to be considered when patients present very early to a community hospital and need to be triaged to an endovascular capable hospital. If the predicted infarct

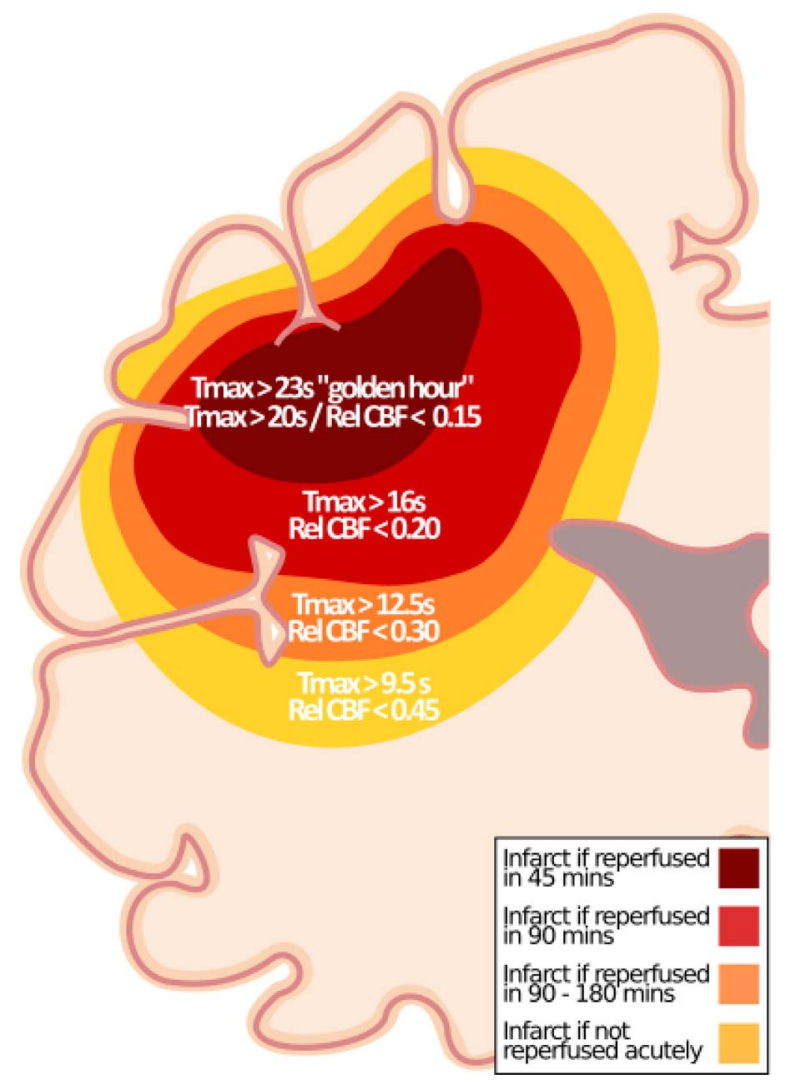

Figure 1: Updated hypothetical model for ischemic core prediction. ${ }^{2}$ In addition to previously published thresholds, ${ }^{2}$ thresholds for "golden hour" patients (Tmax $>23$ seconds) and for patients imaged between 60 and180 minutes after stroke onset (Tmax $>20$ seconds) who achieve reperfusion within 45 minutes of CTP are shown along with the corresponding relative $C B F$ threshold. size using these thresholds is moderate to large, an argument could be made for futility of transfer. A larger sample will be needed however to better understand the biological underpinnings behind our work and to increase generalizability of these CTP thresholds.

\section{ACKNOWLEDGEMENTS AND FUNDING}

The authors thank the Calgary Stroke Program Team, Calgary, Alberta, Canada, and University Hospital.

This study is funded through an operating grant (PRoveIT) from the Canadian Institute of Health Research.

\section{Disclosures}

BKM, MDH, MG, AMD, and TYL have a patent pending on systems of triage in acute stroke. MDH, MG, AMD, TYL, and BKM hold stock in QuikFlo Health Inc. MG has a patent on systems of stroke diagnosis using multiphase computed tomographic angiography and a licensing agreement with GE Healthcare for the same. MDH and MG have a research grant with Covidien to conduct clinical trials. TYL licenses CT Perfusion software to GE Healthcare. The remaining authors have nothing to declare.

\section{SupPlementary Material}

To view supplementary material for this article, please visit https://doi.org/10.1017/cjn.2017.287

\section{REFERENCES}

1. Goyal M, Demchuk AM, Menon BK, et al. ESCAPE Trial Investigators. Randomized assessment of rapid endovascular treatment of ischemic stroke. N Engl J Med. 2015;372: 1019-1030.

2. d'Esterre CD, Boesen ME, Ahn SH, et al. Time-dependent computed tomographic perfusion thresholds for patients with acute ischemic stroke. Stroke. 2015;46:3390-97.

3. Menon BK, d'Esterre CD, Qazi EM, et al. Multiphase CT angiography: a new tool for the imaging triage of patients with acute ischemic stroke. Radiology. 2015:142256.

4. Bivard A, Levi C, Krishnamurthy V, et al. Defining acute ischemic stroke tissue pathophysiology with whole brain ct perfusion. J Neuroradiol. 2014;41:307-15. 
5. Bivard A, Levi C, Spratt N, Parsons M. Perfusion ct in acute stroke: a comprehensive analysis of infarct and penumbra. Radiology. 2013;267:543-50.

6. Campbell BC, Christensen S, Levi CR, et al. Cerebral blood flow is the optimal ct perfusion parameter for assessing infarct core. Stroke. 2011;42:3435-40.
7. Qiao Y, Zhu G, Patrie J, et al. Optimal perfusion computed tomographic thresholds for ischemic core and penumbra are not time dependent in the clinically relevant time window. Stroke. 2014;45:1355-62. 